\title{
Atributos, actitud y anagnórisis del personaje de Auristela en Cervantes y Calderón de la Barca: un estudio comparativo

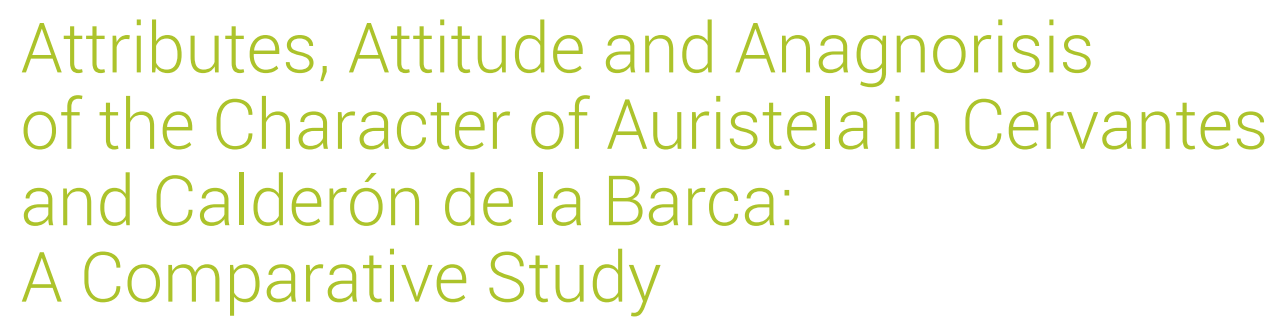

\section{Rocío Arana Caballero}

https://orcid.org/0000-0002-0186-026X

Universidad Internacional de la Rioja

ESPAÑA

rocio.arana@unir.net

[Hipogrifo, (issn: 2328-1308), 9.2, 2021, pp. 753-771]

Recibido: 04-12-2020 / Aceptado: 28-12-2020

DOI: http://dx.doi.org/10.13035/H.2021.09.02.54

Resumen. El presente artículo ofrece una comparativa de dos personajes y una sola nomenclatura, Auristela, en la obra de Cervantes y en la de Calderón. Tras un estado de la cuestión bibliográfica se aborda el asunto desde un análisis del personaje en dos obras de estos dos celebrados autores del Siglo de Oro español: Los trabajos de Persiles y Sigismunda, por un lado, y Auristela y Lisidante, por otro, para destacar semejanzas y diferencias a lo largo de la trama.

Palabras clave. Auristela; Cervantes; Calderón; anagnórisis; Siglos de Oro.

Abstract. This paper offers a comparison of two characters and a single nomenclature, Auristela, in the work of Cervantes and Calderón. After a state of the bibliographic question, the matter is approached from an analysis of the character in two works by these two celebrated authors of the Spanish Golden Age: The works of Persiles and Sigismunda, on the one hand, and Auristela and Lisidante, on the other, to highlight similarities and differences throughout the plot.

Keywords. Auristela; Cervantes; Calderón; Anagnorisis; Golden Age. 


\section{INTRODUCCIÓN: TÉRMINOS DE LA COMPARACIÓN Y OBJETIVO DEL ESTUDIO}

El evocador nombre de Auristela surca la literatura caballeresca del siglo de Oro: desde su aparición como nombre figurado de Sigismunda en el Persiles, obra póstuma de Cervantes publicada en 1617, hasta su omnipresencia (incluso en el título), en una de las comedias novelescas o palaciegas de Calderón de la Barca que, representada en el Coliseo del Buen Retiro en 1660, fue publicada en 1663'.

Un mismo nombre que se repite en dos textos muy distintos pero que comparten un mismo espacio dramático, un telón de fondo caballeresco: de aventuras, ficcionalizado e idealizado. La novela cervantina, en la que sabemos que el autor puso todo su empeño y que fue eclipsada por la crítica durante muchos años, aunque en su época tuviera gran éxito, ha sido calificada con distintos apellidos: bizantina, de aventuras griegas..., si bien el propio autor utiliza el subtítulo de «septentrional» para darnos a entender la procedencia de sus protagonistas, claves en este estudio. Se trata de dos príncipes escandinavos que, enamorados y prometidos en secreto, viajan de incógnito desde sus lejanas islas a Roma, para contraer matrimonio y crecer en su formación religiosa en la ciudad eterna. Durante el camino sufrirán abundantes aventuras y desventuras (de ahí los «trabajos» en la acepción cervantina), y se les unirá una pléyade de personajes secundarios que hacen de esta novela un singular retablo narrativo, al que en el pasado achacaron injustamente los defectos de inverosimilitud e incongruencia, sin atender a las convenciones propias de su género.

Fue Avalle-Arce quien afirmó que «el Persiles empieza en el punto preciso en que acaba el Quijote»2: ambas obras alcanzan una cumbre, pero mientras que en el Quijote «incorpora lo cómico», con el Persiles hace lo propio con «lo maravilloso»3, aunque siempre buscando la verosimilitud, como recoge en su estudio Mercedes Blanco al analizar diversos puntos de la novela:

El Arnaldo del Persiles es, como Altayes, un príncipe privado transitoriamente de su reino por seguir los pasos de una bellísima princesa que anda por tierras lejanas, pero Cervantes, más sobriamente que su predecesor, se contenta con hacerle príncipe heredero de Dinamarca, país que tiene no sólo la virtud de sonar a cosa real, sino hasta de existir de verdad ${ }^{4}$.

Por su parte, Auristela y Lisidante es una comedia de amor, honor y celos, los «hilos que tejen la trama de las comedias palaciegas, mitológicas o de costumbres»5. Concebida para representarse en palacio ante nobles, lo que pretende causar es admiración: por eso vuelca el dramaturgo toda su fantasía y concibe islas lejanas, mundos caballerescos y nobles con una capacidad de lealtad, valentía y sentido del honor superlativas.

\footnotetext{
1. Di Pinto, 2002.

2. Avalle-Arce, 1975, p. 212.

3. Lozano-Renieblas, 1998, p. 8.

4. Blanco, 2004, p. 20

5. Regalado, 1995 II, p. 549.
} 
La trama abarca las peripecias de Lisidante, príncipe de un imaginario país llamado Epiro, que acudió al reino de Grecia para participar en unas fiestas y en un torneo mata por accidente a su rey. Una serie de equívocos propios de las comedias áureas dificulta aún más la acción, aunque el nudo reside en que Lisidante está enamorado de Auristela, una de las dos hermanas y herederas del fallecido monarca. Se crea así un enredo muy del gusto del público siglodorista, pero con tintes de drama por las controversias entre amor, honor y amistad que acometen a los diversos personajes de la historia.

Tras este breve resumen de ambas obras, cabe definir el objetivo del presente artículo: buscar rastros del mencionado personaje calderoniano en la novela de Cervantes, no para elucubrar sobre una posible fuente de la comedia (asunto muy cuestionable), sino para comparar el tratamiento que ambos autores dan a un carácter novelesco y caballeresco que, si no es idéntico (no puede serlo ya que la convención literaria en la que se mueven una comedia y una novela no son las mismas) sí comparte nombre: empecemos por esta cuestión.

Pero antes, permítasenos un breve apunte sobre la impronta del mundo cervantino en el teatro de Calderón.

\section{CERVANTES Y CALDERÓN DESDE LA BIBLIOGRAFÍA: ENCUENTROS Y DESENCUENTROS}

Para el caso que nos ocupa y desde la bibliografía primaria, las recientes edi-

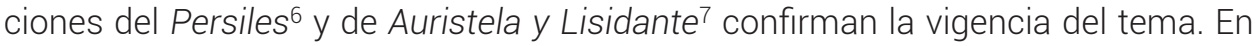
el primer caso, como colofón de múltiples estudios secundarios sobre esta novela cervantina que, tras haber sido ignorada o cuestionada, ve volcarse sobre ella en un goteo ininterrumpido todo tipo de lecturas totalizadoras ${ }^{8}$, o parciales. En el segundo, como primicia de una comedia que hasta ahora tal vez no llamó la atención de los calderonistas tanto como mereciera.

Las relaciones entre Cervantes y Calderón, la vinculación de motivos, personajes... han sido sondeados desde tiempo atrás. A los trabajos pioneros se sumaron los de Pereira-Zazo (1989) y Arellano (1999)... por delimitar y no extendernos exhaustivamente en este apartado bibliográfico. El primero, «Teatrum Mundi: Cervantes y Calderón», a pesar de un título que genera amplias expectativas, es simplemente un enfoque específico sobre las metáforas teatrales y su papel modificador del sistema de lugares comunes, ya que - según él- «la historia del arte es la articulación de la historia de los conflictos sociales» ${ }^{9}$. Desde esta perspectiva, estudia en profundidad Cervantes (Quijote, Novelas ejemplares, El retablo de las maraviIlas...) frente a Calderón, al que dedica menos atención ${ }^{10}$. Algo parecido sucede con el de Regalado de 1999 que los enfrenta en torno a «El gran teatro del mundo».

6. Fernández, 2018

7. Arana, 2012.

8. Mata Induráin, 2004.

9. Pereira-Zazo, 1989, p. 191

10. Mientras el primero «reorganiza el complejo de las metáforas teatrales para poner en evidencia el carácter artificioso o aparente de la clasificación estamental de los individuos», hay «otros que la con- 
Arellano trabaja las relaciones entre ambos escritores en profundidad y desde una perspectiva mucho más amplia. Comienza estableciendo un diálogo con la bibliografía anterior (Sánchez, Wilson, Canavaggio, R. ter Horst, Abrams..., matizando sus asertos desde un «modesto objetivo» que no resulta tal, sino que va mucho más allá:

[...] recapitular y reexaminar las opiniones vertidas por la crítica, reuniendo y sintetizando lo dicho por estudiosos precedentes, intentando precisar algunos aspectos sobre los mecanismos de adaptación y el sentido de estas apropiaciones calderonianas de los textos cervantinos, para ordenar, quizá el conjunto de una manera más completa ${ }^{11}$

Un planteamiento muy ambicioso que cumple con creces, por lo que es de rigor citarlo como marco del trabajo que aquí se presenta. Sus afirmaciones esclarecen el estado de la cuestión: el relato y la comedia tienen imperativos genéricos muy distintos..., se impone actuar con prudencia frente a supuestas fuentes ya que, entre otras cosas «la posible influencia cervantina queda muy restringida por el fracaso de la fórmula teatral de Cervantes frente a la lopiana» ${ }^{12}$. Tras esta primera parte de su investigación y recordando que Calderón reconoció siempre el genio fabulador de Cervantes, se centra en los marcos diferentes de inserción y las diferentes necesidades y convenciones de escritura. Y lo hace exhaustivamente tanto en las referencias microtextuales del primero en el segundo como en las macrotextuales, para concluir lo siguiente:

Podemos resumir que el número de referencias concretas a Cervantes o su obra en el teatro de Calderón es bastante elevado, pero en buena parte están constituidas por menciones momentáneas que revisten poca funcionalidad o trascendencia ${ }^{13}$.

No obstante, reconoce en ambos un deseo de multiplicar los niveles de sentido, el juego intertextual y la plurisignificación.

En la bibliografía citada hasta ahora en principio no aparecen referencias que tengan alguna relación con la Auristela cervantina. Por ello parece interesante reseñar tres artículos que sí lo hacen: el de Mata Induráin, «Bodas místicas vs bodas humanas en el Persiles de Cervantes: Sosa Coitiño y Leonora Pereira, contrapunto de Periandro y Auristela» (2005); el de Gherardi, «Periandro y Auristela: su contribución a la teoría y a la práctica del «mundo al revés» (2010); y el de Colahan, «Auristela y Cenotia, personalidades horacianas en el Persiles» (2012), por citar algunos. Este último enlaza con las tesis expuestas en el siguiente epígrafe y se verá allí.

sideran como una realidad segura e inmutable, sea apelando a una postura nihilista (estoicos) o a una actitud trascendente cristiana», dice Pereira-Zazo, 1989, p. 190. Esta segunda actitud correspondería a Calderón en obras como El gran teatro del mundo y No hay más fortuna que Dios.

11. Arellano, 1999, p. 10.

12. Arellano, 1999, p. 12

13. Arellano, 1999, p. 33 
Mata Induráin revisa la historia de Leonora como contrapunto de la de Auristela, el amor divino frente al matrimonio humano, «una de las historias que enlazan los sucesos del Norte bárbaro con los del Sur católico, reforzando la unidad de la novela» ${ }^{14}$. Y resalta como una constante de la novela cervantina «que los amores honestos encaminados al matrimonio, salgan finalmente triunfantes» ${ }^{15}$. Convencido de ello, añade:

Para la pareja protagonista, el deseo más importante es el de llegar a Dios: el peregrinaje de los cuerpos les ha llevado a Roma, el movimiento de las almas los conduce hasta la divinidad. Auristela y Periandro confirman que es posible llegar a ese sosiego divino a través del matrimonio ${ }^{16}$.

Un planteamiento muy cercano al de Calderón y asumido implícitamente por la Auristela de su comedia.

Flavia Gherardi plantea la doble aparición de Periandro vestido de mujer y Auristela en hábito de varón como un ejemplo del «mundo al revés», «alteración general del ser y de sus etiquetas identitarias que se aplica a una serie de elementos más extensa que el simple atuendo: el cambio de patronímico [...], el cambio de status [...] y otras formas de encubrimiento» ${ }^{17}$. Y concluye:

El Siglo de Oro ya no le confía al «mundo al revés» la expresión de los trastornos de la realidad exterior, o por lo menos, ésta ya no es su única función, sino el más poderoso bouleversement de su conciencia desbarajustada, acarreado por la interiorización de los conflictos y desequilibrios interiores ${ }^{18}$.

Si así fuera, la Auristela de Cervantes resultaría mucho más moderna y compleja psicológicamente que calderoniana.

En este breve repaso y dejando a un lado otros estudios, habría que anotar como marco para el trabajo que aquí se presenta el artículo de Alfredo Rodríguez LópezVázquez, «Ariosto, Cervantes y Calderón: códigos y géneros del Renacimiento al Barroco» ${ }^{19}$, porque amplía los dos autores estudiados remontándose a la bibliografía italiana. Ante todo recuerda el impacto de Ariosto en la Europa de la época20 desde premisas obvias:

\footnotetext{
14. Mata Induráin, 2005, p. 107.

15. Mata Induráin, 2005, p. 107.

16. Mata Induráin, 2005, p. 109.

17. Gherardi, 2010, p. 87. Si bien es cierto que el vestido funciona como catalizador de identidad, su interpretación de este travestismo como literatura carnavalesca, por un lado, y alegórica en relación al Andrógino, por otro, resulta demasiado forzada.

18. Gherardi, 2010 , p. 92.

19. Rodríguez López-Vázquez, 2001, pp. 61-76.

20. Fue «editado por primera vez en 1516, alcanzó las 154 ediciones en el siglo XVı, y 24 más en los treinta primeros años del XVII» (Rodríguez López-Vázquez, 2000, p. 61).
} 
Ariosto influye en los escritores del siglo XVI y entra en la modernidad a través de Cervantes, fijando los códigos, por vía paródica y percepción realista, sobre los que se construye ese gran monumento que es el Quijote, y llega después a los públicos europeos a través del teatro calderoniano ${ }^{21}$.

El investigador insiste en el destinatario, lo que explica que el restringido y culto lector de Ariosto del Renacimiento se expanda a través del teatro calderoniano: «la media docena de obras que Calderón escribe a partir de los personajes ariostescos, ha tenido sin duda más público en la Europa del XVIII que lectores en el XVI. La diferencia entre el género épico y el dramático es radical en el orden de la recepción»-afirma22. Y además en los años anteriores a La vida es sueño, Calderón «está explorando el mundo cervantino, el de Ariosto y las novelas de caballerías» ${ }^{23}$ en parodias textuales y gestuales, en transcodificaciones de célebres fragmentos del Orlando... Para el investigador es evidente «la influencia que Ariosto tiene en el segundo estilo calderoniano, tanto en el léxico como en las configuraciones imaginarias de los personajes» 24 .

En resumen, lo caballeresco como herencia de Ariosto recala en La puente de Mantible calderoniana ${ }^{25}$ y, con las salvedades oportunas, establece un lazo entre Cervantes y Calderón. Porque

no se limita en la comedia calderoniana a esas obras que arrancan de asuntos épico-caballerescos (El conde Lucanor, El jardín de Falerina, Auristela y Lisidante, El castillo de Lindabridis, Hado y divisa de Leonido y Marfisa), sino que invade con gran variedad de matices e intenciones las comedias llamadas palaciegas y las de costumbres de ubicación madrileña o urbana que logran la máxima complicación del enredo ${ }^{26}$.

El propio Regalado marca una discutible distancia, que no es asunto de esta investigación, entre Cervantes y Calderón al afirmar que «los personajes calderonianos hacen gala de un gusto por la novela de caballerías, pólvora de la imaginación que la sátira de Cervantes no logró anegar»²7.

\footnotetext{
21. Rodríguez López-Vázquez, 2000, p. 61.

22. Rodríguez López-Vázquez, 2000, p. 61.

23. Rodríguez López-Vázquez, 2000, p. 70.

24. Rodríguez López-Vázquez, 2000, p. 75. El estudio es minucioso e incide en varios ejemplos relacionados con lo carnavalesco, o el vuelo maravilloso «que está en la construcción de lo imaginario, asociado a ese heredero de Pegaso que es el Hipogrifo».

25. «En La puente de Mantible, Calderón acomodó la inspiración al asunto épico-fantástico-caballeresco que desarrolló sin excluir la intensidad de una sublime expresión lírica o la parodia del impulso épico» (Regalado, 1995 II, p. 580).

26. Regalado, 1995 II, p. 581.

27. Regalado, 1995 II, p. 499.
}

HIPOGRIFO, 9.2, 2021 (pp. 753-771) 


\section{AURISTELA: UN NOMBRE, DOS IDENTIDADES. CÓMO PRESENTAN CERVANTES Y CALDERÓN AL PERSONAJE}

La nomenclatura cobra vital importancia en las dos obras y en el caso que nos ocupa es común a ambas. El nombre de un personaje no resulta baladí, ya que identifica al que lo posee, le conforma o define. En el caso de Auristela, la etimología latina resulta bastante clara: de aurum, «oro» y stella, «estrella» nace esta conjunción, la estrella de oro. Auristela es, entonces, esa estrella de oro en ambas obras, pero en cada una esa forma de llamarse redundará en la trama y en su propio carácter, de forma distinta.

En el epígrafe anterior se mencionó una diferencia visible entre los textos literarios que en este artículo se comparan: la del género literario. Otra más sutil pero no menos importante es la mentalidad, sensibilidad y cosmovisión de ambos autores: cincuenta años separan las génesis de los dos personajes, suficientes como para que en el caso de la novela se le trate con una visión más renacentista y en el de la comedia, plenamente barroca. «En la transición del Renacimiento al Barroco, de Ferrara a Madrid hay un cambio de código y de receptor», como dijo en su momento Rodríguez López-Vázquez ${ }^{28}$.

Como recientemente ha mostrado Kroll29, Calderón cuida mucho la construcción de su comedia. Nada o casi nada es gratuito en ella. Por eso volvamos a la cuestión del nombre: «estrella de oro». El oficio de una estrella es, por un lado, alumbrar como lo hacen ambos personajes con su belleza, pero también nos enseña el camino. Analicemos ambas funciones.

En primer lugar, una estrella resplandece gracias a su belleza, virtud de claro sesgo alegórico en cuanto neoplatónico que destaca en la Auristela cervantina. En palabras de Ermanno Caldera:

El recurso más evidente, el que nos impresiona en sumo grado, es la omnipresencia de la hermosura, al punto que podríamos afirmar que el Persiles ha sido concebido esencialmente sub specie pulchritudinis. Por otro lado, hace falta subrayar que el detalle estético es el que más les confiere a unas figuras el debido relieve y el que más despierta y atrae la atención del observador ${ }^{30}$.

Una hermosura y un resplandor que en el caso de esta dama no se revisten de deseos pasionales sino de un misticismo neoplatónico. No son pocos los críticos que han aludido a su parecido con la Virgen María. Efectivamente, esta «estrella de oro» tiene en Cervantes claras reminiscencias cristianas, como apuntó Clark Colaham quien rescata huellas de esta utilización retórica en los epodos de Horacio, que Cervantes debió de conocer ya que en 1599 se realizó la primera traducción española de todo el corpus horaciano. Colaham recuerda que, junto al sentido divino e incluso mariano de la frase, la traducción castellana añade una frase que

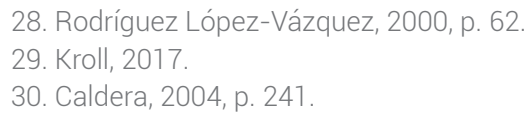


encaja de forma sorprendente en la trama: tu buena yras como estrella de oro (astra) a las estrellas donde estaras colocada y tenida por Diosa. Las palabras y tenida por Diosa hacen pensar inmediatamente en la apariencia como diosa de Auristela en la isla de los Pescadores... ${ }^{31}$

En definitiva, Cervantes -y siempre según Colahan- encontró en Horacio dos tipos de mujer. La virtuosa (Estrella de Oro) y la hechicera, a la que dedica bastantes páginas en su investigación, pero que no es pertinente en nuestro trabajo.

Volvamos entonces a las atribuciones de Auristela: bella y con una función segunda, la de guiar. Se ha convertido ya en tópico entre los estudiosos de esta obra el destacar el hecho de que Auristela es quien guía a lo largo de la acción los pasos de Periandro, el «peregrino» por excelencia. Idea reforzada por Ignacio García Aguilar en sus notas a la reciente edición del Persiles, donde también relaciona este personaje con el de María «bajo la advocación Stella Maris»32.

Esta labor de "brújula" era posible gracias no solo a su hermosura sino, sobre todo, a su sin par discreción; y por eso cuando esta se ve en peligro (asunto que se tratará detenidamente más tarde), también el viaje de Periandro parece carecer de sentido por momentos. Tal vez por esa razón, este rasgo característico del personaje es casi lo primero que se nombra al describirlo por primera vez: es sabido que entre las virtudes que debían adornar en la época a una dama digna de amar / de ser amada destacaba esta, una mezcla entre honestidad y sabiduría que si se daba en grado sumo equivalía a la encarnación de la perfección. Así es presentada Auristela ante el público lector:

De tanta hermosura que entre las que hoy viven en el mundo y entre aquellas que puede pintar en la imaginación el más agudo entendimiento, puede llevar la ventaja. Su discreción iguala a su belleza, y sus desdichas a su discreción y a su hermosura. Su nombre es Auristela ${ }^{33}$.

La hermosura y la discreción refulgen en el personaje de Auristela que, según Juan Ramón Muñoz Sánchez, «se nos ha presentado desde el inicio del relato como la encarnación máxima de la belleza, su sublimación» ${ }^{34}$. Y la forma que tiene Cervantes de describirnos ambas cualidades es muy renacentista: basta con nombrarlas y ponderarlas como las mayores que existen en la tierra y que pueda juzgar un hombre. En el resto del capítulo y en los siguientes, diversos personajes continúan dándonos noticia de tal dama sin que esta aparezca aún en escena.

31. Colaham, 2012, p. 174. Los estudios críticos sobre novela bizantina siempre suelen recoger «un par de episodios en los que uno de los dos protagonistas (masculino y femenino) se presenta en clara asociación identificativa con un dios o una diosa [...]. Pensando Cervantes en tal rasgo genérico, el topar con tenida con Diosa como calificativo de una mujer descrita como sumamente virtuosa y calificada de Estrella de Oro, le podría haber sugerido lo apropiado del nombre para su mujer protagonista» (Colahan, 2012, p. 175).

32. García Aguilar, 2018, p. 22

33. Cervantes, Los trabajos de Persiles y Sigismunda, p. 22.

34. Muñoz Sánchez, 2009, p. 825. 
De Periandro y de Auristela, y de su singular enamoramiento pese a que ambos se den el tratamiento de hermanos, tiene el lector noticias certeras en ocasiones más por lo que deduce e incluso imagina que por lo que se nos muestra en realidad. Un ejemplo lo tenemos muy al principio de la obra, la primera vez en que surgen los celos, durante la conversación que mantienen Periandro y Laurisa (en el capítulo segundo del libro primero): ella presenta a Auristela y habla del amor que esta ha despertado en Arnaldo, príncipe de Dinamarca. De las preguntas que le dirige Periandro sobre esta historia se puede deducir que está enamorado de ella y celoso:

Calló, en diciendo esto, y al mancebo se le atravesó un ñudo en la garganta; pegó la boca con las tablas, que humedeció con copiosas lágrimas, y al cabo de un pequeño espacio le preguntó si, por ventura, tenía algunos barruntos de que Arnaldo hubiese gozado de Auristela, o ya de que Auristela, por estar en otra parte prendada, desdeñase a Arnaldo y no admitiese tan gran dádiva como la de un reino ${ }^{35}$.

Además de su hermosura y discreción, aquí se nos presenta la tercera variable para comprender en profundidad el personaje de la Auristela cervantina: el amor que le profesa su supuesto hermano y los celos que van a probar, a lo largo de toda la obra, ese amor ideal y puro. Preguntar si el príncipe Arnaldo ha tenido relaciones ilícitas con Auristela, o si al menos ella le ha otorgado algún favor del que pueda derivar esperanza, entra en plena colisión con lo que del personaje se nos ha descrito. Una de las raras perfecciones que completan la «discreción» de Auristela es precisamente su honestidad, virtud que es punto clave en la construcción del personaje, como recuerda Aurora Egido:

Honestidad como sinónimo de hermosura parece ser el lema que encarnará a la perfección la propia Auristela como paradigma de ideal platónico cristiano ${ }^{36}$.

Por eso tal pregunta solo se entiende como recurso para dar un claro indicio al lector del ansia que se adivina tras ella, es decir, de los sentimientos y zozobras de Periandro.

Acto seguido aparece Auristela ya in persona: la voz narrativa nos la descubre bajo disfraz varonil en la isla bárbara, a punto de ser asesinada por un terrible puñal. Será su ama Cloelia quien nos indica su identidad y pondera, esta vez sí, su sin igual belleza: «porque es la más hermosa mujer que puede imaginarse. Habla, hermosísima Auristela» ${ }^{37}$.

Cuando se produce el encuentro de ambos enamorados, Periandro le dedica los epítetos «querida mitad de mi alma» y «firme columna de mis esperanzas», lo cual no solo responde a la convención entre enamorados en la época, sino a una idea neoplatónica que trasluce el autor en esta novela: de la belleza se llega a la discreción y de ella, al efecto que causa la amada en el amado. Aquí sale a relucir

35. Cervantes, Los trabajos de Persiles y Sigismunda, p. 24

36. Egido, 1991, p. 212.

37. Cervantes, Los trabajos de Persiles y Sigismunda, p. 32 
la condición de «estrella como guía»: Auristela es y será durante toda la obra, con excepción de unos pocos pasajes de enfermedad y zozobra, el fundamento de la esperanza de Periandro.

Hablemos ahora de la comedia calderoniana. En ella, el nombre de Auristela hace también alusión a la belleza, pero unida a otros efectos y afectos que a continuación se verán. Y al final de la obra se explica el enigma de su nombre con profusión de adjetivos, imágenes, metáforas y recursos ingeniosos, como corresponde a un autor plenamente barroco y a un estilo propio del teatro palaciego del siglo XVII.

La acción comienza, al igual que en la novela de Cervantes, in media res, en un momento doloroso pues el caballero protagonista acaba de matar por un error al hermano de su amada y debe huir. Así se lo aconsejan los príncipes extranjeros, y para obligarle le encarecen el furor de las dos herederas sin saber que él es el afortunado pretendiente de una de ellas:

$\begin{array}{ll}\text { MILOR } & \text { Y más cuando de su trono } \\ & \text { Auristela y Clariana } \\ & \text { descienden, cuyos enojos } \\ & \text { harán mayor el empeño. } \\ & \text { Con esa disculpa, tomo } \\ \text { LISIDANTE } & \text { aquel caballo, y del monte } \\ & \text { a lo intrincado me acojo. } \\ & \text { Bien que, perdida Auristela; } \\ & \text { para qué el huir otorgo? }\end{array}$

En este caso, más que belleza o discreción se hace hincapié en la indignación natural que sentirá la dama y en el triste fin de las aspiraciones amorosas del caballero. En la siguiente escena se nos muestra a la misma Auristela, por lo que no debe encarecer ningún poeta su hermosura. $Y$ aparece ante nosotros envuelta en el que será el quid de su carácter como protagonista, el nudo, el problema que ha de resolver en su interior: el irreconciliable binomio entre amor y odio, o la dignidad de heredera, que veremos en siguientes epígrafes.

Será hablando a su escudero, el gracioso Merlín, cuando Lisidante se refiera por primera vez a Auristela, y aquí sí aparecen los adjetivos y sustantivos de rigor, concernientes a su belleza:

$$
\begin{aligned}
& \text { Nunca de Auristela bella } \\
& \text { admirara la hermosura }{ }^{39} \text {. }
\end{aligned}
$$

En un tercer momento aparece Auristela, que hablando en confidencia con su criada Flérida le confiesa su amor por Lisidante y su imposibilidad de sofocarlo a pesar de la ofensa. 
Durante el resto de la obra, hasta llegar al desenlace final, se hacen algunas alusiones a la belleza de Auristela pero siempre en clave cortés o galante, al uso de los pretendientes del género y la época. Así, Licanoro que desea no tanto su mano como su reino se expresa de forma correcta pero artificiosa:

LICANORO

Yo,

que de tus rayos divinos

así humano girasol

idolatraba los visos 40

Todo coopera a que el personaje de Licanoro, adversario de Lisidante en sus pretensiones amorosas, se nos haga antipático: la forma que tiene de dirigirse a Auristela dista mucho de la emoción que se trasluce en las primeras palabras que le dirige Lisidante:

\begin{tabular}{|c|c|}
\hline LISIDANTE & $\begin{array}{l}\qquad \text { Si tú has dicho } \\
\text { que el no verme es tu consuelo, } \\
\text { y con mi muerte te libro } \\
\text { de este susto en que te ofendo } \\
{[\ldots . .} \\
\text { Venid, vengad a Auristela, } \\
\text { que Ilora de haberme visto... }{ }^{41}\end{array}$ \\
\hline
\end{tabular}

En conclusión: el personaje de Auristela en Cervantes aparece más como un arquetipo platónico de belleza, aunque menos hierático y plano de lo que a veces la crítica se ha empeñado en denostar, pues se traslucen y presienten ya conflictos que serán eje central de la obra.

Por otra parte, la Auristela de Calderón, siendo también muy hermosa como confiesan distintos personajes a lo largo de las tres jornadas, se nos muestra con rasgos más humanos: su posible ira causa temor, su pérdida causa tristeza, y en su interior se labra un combate pues duda entre amar o no amar, algo que nunca ha aquejado a la Auristela cervantina.

\section{AURISTELA A LO LARGO DE LA TRAMA: EL ARQUETIPO Y EL PERSONAJE}

A lo largo de la novela y de la comedia, las dos Auristelas despliegan su hermosura física junto a otros rasgos de carácter que las alejan de unos tópicos y las acercan a otros; pero al menos les dan relieve al hacerlas más humanas. En este epígrafe se desarrollarán tales características y acciones.

Como ya se ha expuesto lo concerniente a la belleza de ambas heroínas, ahora se estudiarán los efectos que causa en los demás personajes. Tan solo cabe añadir que, en la explicitación de semejante rasgo físico, tanto Miguel de Cervantes como Pedro Calderón de la Barca beben de las mismas fuentes arquetípicas, a pesar de

40. Calderón, Auristela y Lisidante, p. 192.

41. Calderón, Auristela y Lisidante, p. 195. 
pertenecer a corrientes literarias dispares. Cervantes, que en muchos aspectos se puede considerar ya casi barroco (como sucede en la segunda parte del Quijote), resulta renacentista en su forma de vertebrar la novela, logrando unidad en la diversidad, así como en los arquetipos petrarquistas y neoplatónicos que le inspiran. Según Aurora Egido:

El Persiles contiene una apretada y varia filografía en la que es fácil entrever la fusión de corrientes diversas entre las que no faltan restos del amor cortés junto al petrarquismo, el neoplatonismo y las huellas de Erasmo ${ }^{42}$.

Uno de estos topos de los que hay que hablar es precisamente la perfecta correspondencia entre belleza de cuerpo y de alma, que a su vez es solo un reflejo del fulgor divino, respondiendo a ideales neoplatónicos imperantes en la época que son tan caros al Cervantes idealista y tan propios de la novela bizantina, como defienden Mata (2004) y Muñoz Sánchez:

Una belleza física que, lógicamente, es el reflejo de la espiritual, pues, efectivamente, Auristela es, como su hermano-amante, un dechado de virtudes morales y ejemplares. Que así sea es una necesidad perentoria del género al que pertenece el Persiles en función de la ligamen platónico entre amor y belleza ${ }^{43}$.

Los efectos que causa la apariencia de ambas Auristelas resultan muy dispares: en Periandro despierta la calma y se convierte en su norte, así como en Arnaldo a pesar de la imposibilidad de su amor; mientras que la Auristela de Calderón evoca con su belleza altiva otros sentimientos menos elevados o positivos: temor, dolor, orgullo herido, además de estupor y asombro helado, como se ha visto en el anterior epígrafe. Esta diferencia se explica debido a la disparidad de tesituras en ambos protagonistas masculinos: Periandro, a pesar de no estar exento de celos y otras zozobras del espíritu, no puede dudar del futuro buen fin de su amor, si atendemos a la nunca desmentida honestidad y fidelidad de su amada. En cambio, Lisidante ya ha dado por arruinadas todas sus aspiraciones: «Bien que, perdida Auristela.... ${ }^{44}$.

Si analizamos las reacciones de Periandro y de Lisidante al principio de cada obra, veremos que el héroe cervantino estaba deseando hallar a Auristela, mientras que el calderoniano rehuía el encuentro, no por desvío sino debido al temor, aunque cuando este sucede se muestra sugestionado por la belleza de su dama. Comparemos las palabras que ambos protagonistas dirigen al objeto de sus desvelos al tenerlo presente por vez primera, tras tantas desdichas:

- ¡Oh querida mitad de mi alma! ¡Oh firme columna de mis esperanzas! ¡Oh prenda, que no sé si diga por mi bien o por mi mal hallada, aunque no será sino por bien, pues de tu vista no puede proceder mal ninguno!45. 
Un discurso claramente renacentista en el que evoca, como bien apunta García Aguilar reminiscencias garcilasianas presentes también, y de forma directa, a comienzos del capítulo octavo del tercer libro del Persiles. Razones, de cualquier manera, bien distantes de las que dirige Lisidante a Auristela en la comedia calderoniana:

LISIDANTE $\quad$ ¿Si es fantasma de la idea?
$\begin{aligned} & \text { [...] } \\ & \text { ¿Cómo, siendo la deidad } \\ & \text { a quien mis hados dedico } \\ & \text { por pasar a ser milagros } \\ & \text { empiezan siendo prodigios? }{ }^{46}\end{aligned}$

Tras este momento de reunión, la Auristela del Persiles se muestra amorosa, mientras que la calderoniana permanece altiva hasta el final de la escena: en efecto, se sucede un diálogo de amor y despecho, en el que la dama actúa como fiscal; pero cuando el galán se acusa no quiere que sea descubierto.

\begin{tabular}{ll}
$\begin{array}{ll}\text { AURISTELA } \\
\text { LISIDANTE }\end{array}$ & No des voces. \\
& \multicolumn{1}{c}{ Si tú has dicho } \\
& que el no verme es tu consuelo \\
& yo de Polidoro invicto \\
& soy el homicida, yo, \\
& Lisidante, su enemigo: \\
& Venid, vengad a Auristela, \\
& que llora de haberme visto, \\
& venid y en mí... \\
& \\
AURISTELA & calla, calla, mas iqué digo? ${ }^{47}$.
\end{tabular}

Salvadas, como ya se han hecho, las diferencias de género y de convención estilística, la zozobra en ambos encuentros posee causas muy diversas: mientras una conduce a la alegría, la otra nada en el infortunio asombrado e incierto.

Uno de los momentos más arquetípicos y a la vez más bellos del Persiles es aquel en el que, enferma de amor Auristela ve marchitarse sus encantos físicos, pero Periandro continúa amándola pues ve su belleza interior. Es cierto que este amor constante ha suscitado algunas interpretaciones freudianas como la de Mercedes Alcalá Galán:

Por su parte el único que la ama en su enfermedad y mantiene su compromiso de entrega hacia ella es Periandro/Persiles, pero no por lo que Auristela es en ese momento sino porque lo que fue impide que Periandro la vea tal y como es. El vivo 
recuerdo de su belleza - es decir, de una Auristela con todo su valor- se impone como una realidad más poderosa que la actualidad que el amante no puede ver en todo su horror ${ }^{48}$.

Más plausible parece la versión que habla del perfecto amor sin fisuras de Periandro ${ }^{49}$ : aplicarle conceptos modernos resulta un peligroso anacronismo y rompe todas las convenciones del género. Tampoco nos parece correcto pensar que Auristela sea solo un foco de atracción y seducción pasivo, como defiende la autora al afirmar que el rasgo que mejor las define, tanto a ella como a Dulcinea,

es la capacidad casi inverosímil de deseo que suscitan en otros personajes, lo que está íntimamente relacionado con la valoración que de ellas hacen quienes las aman ${ }^{50}$

pues en esta creación de Cervantes ha dado plenos indicios de desear ella también, y así se revela como capaz de anhelos y de defectos: se ha llegado a repetir que los protagonistas del Persiles son personajes planos, pero Auristela muestra poseer algo más de relieve en estos pasajes en que enferma por culpa de los celos. Así lo indica Muñoz Sánchez:

Auristela no es, como ya hemos dicho, un personaje perfecto, abstracto y acartonado, hecho de antemano de una pieza, sino que, sin disminuir un ápice su ejemplaridad, se mueve en el terreno de lo humano, y, como tal, tiene algunas asperezas que limar o corregir, tal sus desmesurados celos ${ }^{51}$.

Cervantes bebe en Aristóteles por su forma de vertebrar la novela y de buscar la unidad en la variedad y aún la verosimilitud en lo maravilloso, pero también al hablar de la enfermedad del alma como causa de la enfermedad de cuerpo, tal y como recuerda Egido al citar el tratado aristotélico De anima como muy plausible inspiración de todo este episodio ${ }^{52}$. La enfermedad de amor es, según la misma autora, uno de los mayores tópicos literarios. Sin embargo, en una novela bizantina no se trata tan solo de un topos más, sino de una de las pruebas que tienen que sufrir los amantes para depurar su amor:

En contraste con la novela pastoril, donde la virtud es algo consustancial a su mundo, en la bizantina el amor ha de superar, en su perfeccionamiento, una serie de obstáculos y/o pruebas, que inciden sobre la fidelidad y castidad de la pareja protagonista, pudiendo alcanzar un marcado talante simbólico-alegórico y espiritual que culmina en el matrimonio. De este modo, la castidad, y ligada a ella la fidelidad, se convierte en un valor absoluto, especialmente la femenina ${ }^{53}$. 
Por eso parece manchar la inquietante perfección y turbar la aparente quietud de Auristela el demonio de los celos, que para Aurora Egido supone una también una aparente contradicción. Ella lo achaca a la «permanente paradoja que va de los valores positivos y engrandecedores del amor maestro -en la mejor tradición neoplatónica- que impulsan la pasión, a otros de índole escolástica que lo entienden bajo especies de enfermedad, destrucción y muerte» ${ }^{54}$.

Y así, los celos llevan a Auristela a la vanidad por primera vez: «en mí encontrarás hermosura», le dice a un Periandro confuso y asombrado por este atrevimiento de su castísima prometida:

Si por obligaciones va, y vos por ellas encarecéis las hermosuras, la mía os ha de parecer la mayor de la tierra, según os tengo obligado [...]. Te suplico que no te quiten ni borren de la memoria lo que me debes otras ajenas hermosuras ni otras obligaciones; que en la mía y en las mías podrás satisfacer el deseo y llenar el vacío de tu voluntad, si miras que, juntando a la belleza de mi cuerpo, tal cual ella es, a la de mi alma, hallarás un compuesto de hermosura que te satisfaga ${ }^{55}$.

Estas razones eran tan extrañas en Auristela, normalmente tan alejada de vanidad y tentación, que dejaron a su amado «confuso». Periandro, que no está exento tampoco del fuego de los celos, se confunde y aún se atormenta cuando ve a su amada dudar por culpa de este mal.

En el caso del personaje calderoniano, la duda y evolución toma otro cariz. Como ya se ha comentado, su belleza es expuesta mediante adjetivos, invocaciones y metáforas más propias de la convención aurisecular y dramática, pero lo que realmente caracteriza a este personaje, y a su vez muestra al público su posible defecto y humanidad, es el conflicto entre el orgullo y el amor.

Auristela, hermana de Clariana ${ }^{56}$ y heredera del trono, es una consumada experta en el arte de ocultar a todos sus verdaderos afectos, incluso a ella misma y por supuesto a su ofensor, que resulta ser también su enamorado. Así, al encontrarle, lo primero que le dice es:

¡Aun un consuelo que sólo

en tu fuga había tenido,

que era no volver a verte

en mi vida, oh fiero, oh impío,

tirano cruel, me quitas! ${ }^{57}$

54. Egido, 1991, p. 202.

55. Cervantes, Los trabajos de Persiles y Sigismunda, p. 127.

56. Las mujeres en las comedias calderonianas están obligadas «por las circunstancias y las apariencias a defender su honor valiéndose del ingenio, ya que no pueden servirse de la espada. En las comedias de costumbres y cortesanas aparecen un buen número de personajes femeninos dotados de fuerte personalidad, sensibilidad, inteligencia y espíritu de independencia, extraordinarias y exquisitas figuras que contrastan con la hombría de los personajes masculinos» (Regalado, 1995, vol. II, p. 524).

57. Calderón, Auristela y Lisidante, p. 194. 
Pero cuando él da voces para delatarse, lo impide, y se debate entre su amor oculto y su deseo de venganza. Como conclusión del epígrafe, se ha de señalar que es el amor contrariado lo que hermana e identifica la actuación de estos dos personajes que comparten nombre pero no historia.

\section{LA ANAGNÓRISIS EN AMBAS OBRAS: QUIÉN ES AURISTELA Y QUIÉN ES SU AMADO}

La anagnórisis, que tan de moda pusieron en otras áreas autores como Tolkien o Vladimir Propp, este último al hablar de «transformación» 0 «reconocimiento» 58 en los cuentos de hadas, es también un recurso muy propio de la novela bizantina. Recurso acuñado por Aristóteles en su Poética, constituye «una de las partes de la fábula que mejor contribuye a la creación de sorpresa y tensión en la intriga trágica» ${ }^{59}$.También, uno de los casos de asombro que más diferencian a obras que pertenecen al género de lo novelesco y que tratan de la maravilla y la ficción. Con razón apunta Mayer que «Cervantes en esta obra no sólo se inspira en Heliodoro, sino incluso en el mismo Homero» ${ }^{60}$.

Y también, por último, se trata de una figura retórica presente en las dos obras que aquí se comparan. En el caso de la novela cervantina, la anagnórisis afecta no solo a la identidad sino al nombre que, como ya se ha mencionado, es lo que conforma al personaje. Diversos acontecimientos fuerzan lo que Tolkien llamaría mucho tiempo después «eucatástrofe», un final inesperado cuando todo parece irremisiblemente perdido y la boda de ambos amantes puede efectuarse gracias a ella y a la revelación de las verdaderas identidades de los protagonistas.

Así, el auténtico nombre de Auristela solo se dará a conocer en el desenlace, pero a Segismunda también la define el apelativo que ha poseído durante todo el viaje. No en vano se ha repetido hasta la saciedad que la intención de Cervantes al escribir esta obra era construir una novela griega cristianizada, y el asunto de los nombres y del verdadero nombre tienen mucho que ver con este objetivo. No solo por las reminiscencias apocalípticas (será entonces, según la tradición cristiana, cuando se nos dará una piedrecita donde esté escrito nuestro verdadero nombre, ese que solo conocemos cada uno de nosotros y el Cordero), sino por la costumbre de Jesús de bautizar de manera diferente a todos los que serán sus amigos más íntimos. Y ambos nombres conviven, ambos son verdaderos, solo que uno transciende al otro:

Sabido es que en la tradición hebreo-cristiana el cambio de nombre de la persona refleja un cambio de horizonte: Jacob-Israel, Saulo de Tarso-San Pablo61. 
Volviendo al asunto de Auristela/Segismunda, no hay que olvidar que para algunos autores (entre ellos, Alcalá Galán), lo que sucede al final del Persiles no es tanto un caso de anagnórisis como de doble identidad:

El doble, como presencia literaria, funciona -más que como un simple recurso - como una técnica fundamental de narrar un camino para representar la complejidad de la esencia del carácter de ficción ${ }^{62}$.

Puede tratarse, se trata a nuestro parecer de ambas cosas: doble identidad y anagnórisis de «esta mujer con dos nombres, esta peregrina y reina, esposa y hermana respectivamente» ${ }^{63}$.

La anagnórisis final hermana de nuevo a ambos personajes, pero mientras la Auristela cervantina queda convertida en otra persona (o, por mejor decirlo, se revela su identidad al final de la obra, que en eso consiste el recurso aristotélico), en el caso de Calderón es Lisidante quien cobra una nueva identidad, pero en función de su amada. Es entonces el propio nombre de Auristela el que salva a su amado Lisidante, por medio de la explicación del emblema y el mote que hay en su escudo:

\begin{tabular}{|c|c|}
\hline LISIDANTE & $\begin{array}{l}\text { No, que más incluye el mote, } \\
\text { si de descifrarle tratas; } \\
\text { pues mi nombre y el del dueño } \\
\text { que adoro, bien que con tanta } \\
\text { veneración, que ella nunca } \\
\text { lo supo, con cuya salva } \\
\text { puedo explicar qué contiene } \\
\text { [...] } \\
\text { con que el emblema por alma } \\
\text { en stella y auri, lisis } \\
\text { y dante, verás que hallas } \\
\text { Lisidante y Auristela64. }\end{array}$ \\
\hline
\end{tabular}

Por lo que es el nombre de Auristela y su condición de amada de Lisidante lo que revela la verdadera identidad del héroe.

Como conclusión podría afirmarse que, en este caso, Calderón ha dado una vuelta de tuerca al personaje cervantino en la construcción de su identidad: mientras que en el Persiles se desvela desde fuera y al mismo tiempo quiénes son ambos personajes, y acceden tras ello al final feliz que incluye boda, en la comedia calderoniana este esperado y previsible desenlace no sería posible sin que el propio protagonista revelara su verdadero nombre gracias a un cortés juego de palabras que también pone al descubierto su amor y la identidad de su amada: parece que las tres fueran una misma cosa, y sin Auristela no pudiera existir, ni siquiera ser nombrado, el protagonista de toda la acción. 


\section{BiBLIOgRAFÍA}

Alcalá Galán, Mercedes, «La representación de lo femenino en Cervantes: la doble identidad de Dulcinea y Sigismunda», Cervantes. Bulletin of the Cervantes Society of America, 19.2, 1999, pp. 125-134.

Arellano Ayuso, Ignacio, «Cervantes en Calderón», Anales Cervantinos, 35, 1999, pp. 9-35. Reeditado en El escenario cósmico. Estudios sobre la comedia de Calderón, Madrid / Frankfurt am Main, Iberoamericana / Vervuert, 1999, pp. 55-92.

Avalle-Arce, Juan Bautista, «Los trabajos de Persiles y Sigismunda, historia setentrional», en Suma cervantina, ed. Juan Bautista Avalle-Arce y Edward C. Riley, Londres, Tamesis Books, 1973, pp. 199-212.

Avalle-Arce, Juan Bautista, «Tres vidas del Persiles. Cervantes y la verdad absoluta», en Nuevos deslindes cervantinos, Barcelona, Ariel, 1975, pp. 215-243.

Blanco, Mercedes, «Los trabajos de Persiles y Sigismunda: entretenimiento y verdad poética», Criticón, 91, 2004, pp. 5-39.

Caldera, Ermanno, «Con eminencia y aumento (La excelencia en el Persiles)», en Peregrinamente peregrinos. Actas $V$ Congreso Internacional de la Asociación de Cervantistas, ed. Alicia Villar Lecumberri, Lisboa, Fundación Gulbenkian, 2004, pp. 239-248.

Calderón de la Barca, Pedro, Auristela y Lisidante, ed. Rocío Arana, Madrid / Frankfurt am Main, Iberoamericana / Vervuert, 2012.

Cervantes, Miguel de, Los trabajos de Persiles y Sigismunda, ed. Laura Fernández, notas Ignacio García Aguilar y notas complementarias Carlos Romero Muñoz, Madrid /Barcelona, Real Academia Española / Espasa-Círculo de Lectores, 2018.

Colahan, Clark, «Auristela y Cenobia, personalidades horacianas en el Persiles», Anales Cervantinos, 44, 2012, pp. 173-186.

García Aguilar, Ignacio, Notas a pie, en Miguel de Cervantes, Los trabajos de Persiles y Sigismunda, ed. Laura Fernández, notas Ignacio García Aguilar y notas complementarias Carlos Romero Muñoz, Madrid / Barcelona, Real Academia Española / Espasa-Círculo de Lectores, 2018.

Gherardi, Flavia, «Periandro y Auristela: su contribución a la teoría y a la práctica del mundo al revés», Nuevos caminos del hispanismo. Actas del XVI Congreso de la Asociación Internacional de Hispanistas, Paris, 9-13, 2007. Madrid/ Frankfurt, Iberoamericana/Vervuert, 2010, pp. 85-94.

Di Pinto, Elena, «Los mecanismos de la risa: de Auristela y Lisidante y Celos aun del aire matan, a Céfalo y Pocris», en Calderón 2000, ed. Ignacio Arellano, Kassel, Reichenberger, 2002 (I), pp. 997-1006. 
Egido, Aurora, «El Persiles y la enfermedad de amor», en Actas del Il Coloquio internacional de Cervantistas, Barcelona, Anthropos, 1991, pp. 201-224.

Egido, Aurora, «La memoria y el arte narrativo del Persiles», Nueva Revista de Filología Española, 18, 2017, pp. 621-641.

Garau, Jaume, «Predicación y ortodoxia en el Persiles», Anales Cervantinos 45, 2013, pp. 241-268.

Kroll, Simón, Las comedias autógrafas de Calderón de la Barca y su proceso de escritura, Madrid/Frankfurt, Iberoamericana/Vervuert, 2017.

Lozano-Renieblas, Isabel, Cervantes y el mundo del «Persiles», Alcalá de Henares: Centro de Estudios Cervantinos, 1998.

Mata Induráin, Carlos, «El Persiles de Cervantes, paradigma del arte narrativo barroco», en Temas del Barroco hispánico, ed. Ignacio Arellano y Eduardo Godoy, Madrid / Frankfurt am Main, Iberoamericana / Vervuert, 2004, pp. 197-219.

Mata Induráin, Carlos, «Bodas místicas vs bodas humanas en el Persiles de Cervantes: Sosa Coitiño y Leonora Pereira, contrapunto de Periandro y Auristela», en El matrimonio en Europa y el mundo hispánico siglos XVI y XVII, ed. Ignacio Arellano y J. M. Usunáriz, Madrid, Visor, 2005, pp. 95-112.

Mayer, Eric D., «Homer, Heliodorus, and Cervantes: Some Observations on Anagnorisis in Los trabajos de Persiles y Sigismunda (1617)», Comitatus. A Journal of Medieval and Renaissance Studies, 35.1, 2004, pp. 108-123.

Muñoz Sánchez, Juan Ramón, La reescritura en Cervantes: el tema del amor, Madrid, Universidad Autónoma de Madrid, 2009.

Muñoz Sánchez, Juan Ramón, «Reflexiones sobre Los trabajos de Persiles y Sigismunda, historia setentrional», Anales Cervantinos, 47, 2015, pp. 249-288.

Pereira Zazo, Óscar, «Teatrum Mundi: Cervantes y Calderón», Anales Cervantinos, 27, 1989, pp. 187-202.

Propp, Vladimir, Morfología del cuento, Madrid, Fundamentos, 1981.

Regalado, Antonio, Los orígenes de la modernidad en la España del Siglo de Oro. I y II, Barcelona, Destino, 1995.

Regalado, Antonio, «Cervantes y Calderón: el gran teatro del mundo», Anales Cervantinos, 35, 1999. pp. 407-418.

Rodríguez López Vázquez, Alfredo, «Ariosto, Cervantes y Calderón: códigos y géneros del Renacimiento al Barroco», Lenguaje y textos, 16, 2000, pp. 61-76.

Teijeiro Fuentes, Miguel Ángel, «El recurso de la anagnórisis en algunas de las Novelas ejemplares de Cervantes», Anales Cervantinos, 35, 1999, pp. 539-570. 